\title{
El culto a Bolívar y la historiografía venezolana: talla con el historiador Germán Carrera Damas
}

The Cult of Bolivar and the Venezuelan historiography: interview with Germán Carrera Damas

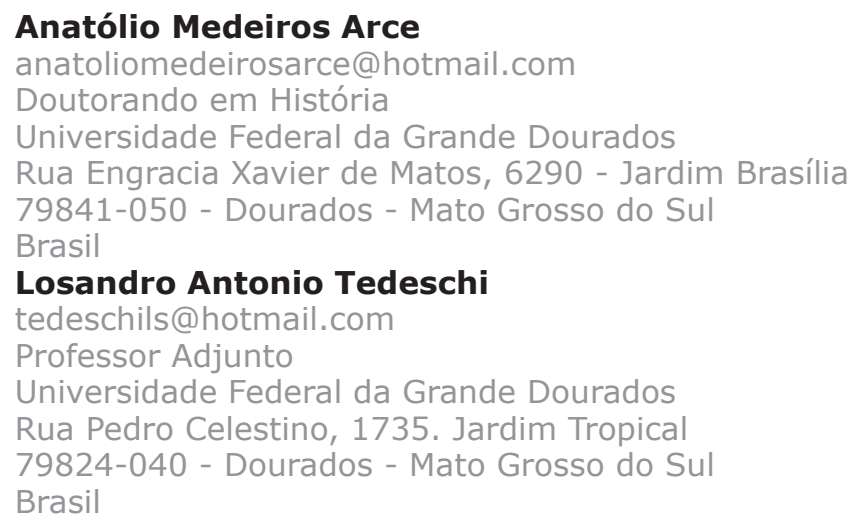

Palabras-clave

América Hispana; Historiografía; América Latina.

200 Keywords

Hispanic America; Historiography; Latin America. 
Germán Carrera Damas es uno de los historiadores más conocidos de Venezuela. Sus libros son muy utilizados, tanto en las universidades como en la academia militar venezolana. Sin duda, una de sus obras más conocidas es el libro El culto a Bolívar publicado en 1970, que va por su séptima edición. Sin embargo, Carrera Damas también escribió otros libros, como Una nación Ilamada Venezuela (1984); Historia de la historiografía venezolana (1961); Rómulo histórico (2013), y otros. Rómulo histórico fue publicado tras el análisis del manuscrito por un conjunto de expertos de distintos ámbitos del conocimiento: historiadores, politólogos, antropólogos, sociólogos y hasta literatos. En la actividad docente, Carrera Damas es Profesor Titular (jubilado) de la Escuela de Historia de la Facultad de Humanidades y Educación de la Universidad Central de Venezuela (UCV) y en la Universidad Nacional Autónoma de México (UNAM). Ocupó la Cátedra Simón Bolívar en la Universidad de Cambridge, Inglaterra, y la inauguró en las universidades de Colonia (Alemania) y Universidad Nacional Autónoma de México. En el servicio diplomático venezolano fue embajador de la República de Venezuela en México, Republica Federal de Alemania y la Unión Soviética.

Esta entrevista con Germán Carrera Damas fue realizada por Anatólio Medeiros Arce y revisada por Losandro Tedeschi. El encuentro fue intermediado y posibilitado por la escritora e historiadora venezolana Mirla Alcibíades. ${ }^{1}$ Los dos autores también hicieron la supervisión final de la entrevista. El método utilizado fue de preguntas abiertas hechas al entrevistado, facultándolo leerlas o no. Carrera Damas optó por no leerlas y autorizó la grabación en audio de la entrevista y su posterior transcripción. La entrevista se desarrolló en la residencia de Carrera Damas, en una mañana de 15 de abril de 2015 en Caracas, Venezuela.

\section{Anatólio Medeiros Arce: Buen día señor Germán Carrera Damas. Con mucho} gusto te hago esta entrevista. Voy hacer la primera pregunta... En líneas generales ¿qué es el culto a Bolívar y qué rol él tiene en la historiografía venezolana?

Germán Carrera Damas (GCD): ¿Tú quieres un libro? [risas]

\section{AMA: Puede ser [risas]...}

GCD: Quiere otra versión del libro [risas]... Bueno... Aquí está dicho. Convirtieron un culto del pueblo en un culto para el pueblo. Ahí está toda la perversión. La gente admiraba a Bolívar. Lo admiraba porque, bueno, las personas no se mueven por ideas, se mueven por creencias y ellos estaban persuadidos de que Bolívar era el cargador de la libertad. Incluso creían que Bolívar era el que había libertado los esclavos y todas estas cosas. Toda la gente tenía devoción por Bolívar y el aparato político, es decir, los mismos que habían acompañado a Bolívar, viendo que la independencia no daba los beneficios 
que se esperaban, casi automáticamente, transfirieron la responsabilidad. Entonces, hicieron de Bolívar el actor único... El actor único. Y a partir de ahí construyeron ese culto que sirve para manipular al pueblo. Apelando a sus sentimientos, genuino, auténtico. Pero, con fines... digamos así, nada genuino, nada auténtico porque es simplemente alcanzar el poder, ejercer el poder y beneficiarse del poder en todo caso. Bueno, la formula que está respondiendo aquí [él se refiere a su libro, El culto a Bolívar] convertir un culto del pueblo en un culto para el pueblo, que es así que se define todo esto. Y lo que vemos ahora, por ejemplo, con el actual presidente cuando él dice "están agrediendo la cuna de Bolívar"; es ruin para lo que está siendo atacado. Eso es para manipular a la gente y así le convierten en villano y lo que se está diciendo se corresponde con los escritos de Bolívar. Pero es una gran farsa. Ahora, hay un culto a Bolívar que ese sí es genuino... Es lo que practica gente como yo. Yo admiro a Bolívar. Pero lo admiro como un gran hombre, como un gran guerrero, como un pensador, pero también como un hombre. Es decir, él vivió situaciones muy difíciles, que cometió graves errores que incluso llegó a ser, él mismo, agente involuntario de descredito de otras personas. Uno de ellos lo practicó a Miranda, pues. Es decir, era un hombre que estaba inmerso en una gran polémica, en una gran discusión. Pero era un hombre que estaba aprendiendo y lo extraordinario es que fue capaz de sintetizar toda la teoría de la Independencia de las colonias hispanas, del imperio hispano-americano, de diseñar una concepción, una política, una estrategia y llevarla a la práctica.

202 Eso lo singulariza como un hombre realmente excepcional... con los errores, por supuesto, y también errores graves, pero con aciertos de tan amplio que superan con mucho lo que podríamos considerar que fueran errores o desaciertos. Pero debemos respetarlo de su integridad, no deificarlo. Porque hizo mucho para ser un hombre y muy poco para ser un Dios. Ese es mi punto de vista sobre el asunto. Mire, el mayor error que se ha hecho Bolívar, lo dice el ilustre historiador americanista el británico, John Lynch, que ha escrito un libro sobre Bolívar (LYNCH 2006). John Lynch llegó a decir en su libro "Aun en los momentos de su decadencia, Bolívar era superior a todos los que lo rodeaban". Yo tengo buena relación con John Lynch, por eso que está en las palabras de él, que son muy valerosas, sobre mi libro. No sé si me permite...

\section{AMA: Sí, sí...}

GCD: Mire, Lynch lo que él habla del libro... y yo le digo a John, porque eso no es un británico [risas], los británicos no son tan impulsivos. Y él me dice, mire, este [Bolívar] realmente era un hombre admirable. Pero, para mí, eso es un reconocimiento que se corresponde. No está diciendo que era un Dios, que era un superhombre... era superior a los que lo rodeaban. Pero eso era proprio de los grandes hombres. Entonces, desde el punto de vista, la misión de Bolívar, si quieren la de un historiador, que él entiende a valorar la obra, valorar sus personajes, pero dentro de su integridad. 
GMD: No exagerado, desorbitado [risas]. Claro. Yo tengo en la mente, la imagen de un... lamentablemente... la imagen de un hombre común, de un obrero como se quiera, en la calle, enfrentándose a una manifestación de viejitas, muchachitos, mujeres ... una de la oposición, y el hombre gritando: "Enemigos de Bolívar" [risas].

\section{Mirla Alcibíades: Sí, una síntesis que ya es todo exacto.}

GCD: Se queda espantoso hasta donde se puede ir y ser fanatizada una sociedad por el uso constante y sistemático, abusivo, de una persona histórica; basándolo en su contenido real y poniéndolo como criterio referencial para todos. Yo hago la broma de preguntarles: bueno ¿qué opinaba Bolívar sobre la bomba atómica? [risas]. No tenemos que llegar a este extremo. Bueno, yo creo que es el máximo de una consciencia histórica. Cualquiera que sea el país, el país donde sea, hacer de una figura la síntesis de esa consciencia histórica. La conciencia histórica es mucho más plural, mucho más diversa, mucho más rica que la vida de una persona. Entonces aquí se llegó a sustituir la consciencia histórica de los venezolanos por lo que se llama el pensamiento o la conciencia bolivariana. Eso es muy perjudicial. Felizmente, ya hay una reacción considerable. Hoy en día hay por lo menos, no sé, cinco o seis obras que llevan adelante esto. Está en la obra de Castro Leiva (1987), en la obra de Manuel Caballero (2007), en la obra de Elías Pino Iturrieta (2014). Hay una serie de obras dónde ellos han desarrollado una serie de aspectos. Aún han dicho que si yo no voy actualizar mi libro. Y les digo, ¿para qué? Yo no soy el dueño del tema. Yo lo plantee en un momento en que consideré que era necesario. Pero ahora lo están desarrollando otros.

¿Por qué crees tú que yo escribí este libro? Fueron razones no académicas, sino como la misión del historiador que práctica una norma. Yo hablo del deber social del historiador. El historiador no puede estar fuera de su tiempo, teniendo el tiempo como tiempo histórico: pasado, presente y futuro. En consecuencia no puede desentenderse de aquellos que constituyen las preocupaciones, las diversidades de su sociedad. Yo comencé a trabajar en eso ya sistemáticamente cuando regresé del exilio. Estuve diez años exiliado durante el gobierno de Pérez Jiménez. Regresé aquí en 58 [1958] y me encontré con que los hombres que estaban planteando de nuevo la democracia en Venezuela estaban utilizando las mismas ideas que había usado la dictadura. Y aquello sí me preocupó. Porque veía que íbamos por un camino malo, en el sentido de que esas ideas de Bolívar corresponden a otro tiempo y fueron pervertidas y utilizadas para justamente dominar y controlar a la sociedad, no para un desarrollo democrático. Y yo escribí este libro para alertarlo, o mejo dicho, con la emoción de que yo iba a alertar a estos dirigentes políticos. Por supuesto nadie lo leyó. Olvídate. E hicieron exactamente lo mismo. Ahora cuando después de tanto tiempo cuando están comenzando a ver las cosas desde otro prisma. Pero la culpa no fue de ellos, la culpa fue mía porque en ese momento yo no había hecho los estudios de 
historia y de historiografía que después yo he hecho. No me había dado cuenta de que entre la proposición de un nuevo conocimiento y la incorporación de este conocimiento a los niveles de la educación, lo mínimo es un cuarto de siglo. Mínimo un cuarto de siglo.... Salí del nivel de la proposición científica y pasé al tema de la incorporación a la conciencia histórica común. Y por lo mismo al nivel escolar. Yo no sé cómo ha sucedido esto en Brasil, yo no lo he estudiado, pero aquí la situación ha sido esta. Creo que en otros países será semejante. Conozco el caso de Colombia, el caso de Ecuador. Ellos no convirtieron a Bolívar en un culto. Pero los peruanos tienen razón para que Bolívar les haga algo. Bueno, Perú era la primera potencia del imperio hispano-americano. Y por órdenes del general Sucre lo convirtieron en un paisito más. Esta era la realidad. Entonces para ellos Bolívar y sobre todo Sucre, no los aceptan. Todavía aún los tratan... Esa era el origen de mis preocupaciones científicas, por cierto. Yo estaba preparando mi obra sobre la historia de la historiografía venezolana y daba cuenta de que el culto a Bolívar era una constante. Pero además de la continuidad política, en este libro se reitera también esa continuidad política, porque después de diez años en el exilio ver que la democracia iba a cometer los mismos errores - y que no se avergonzaron en utilizar las mismas armas que se usaron contra ella - me parecía un gran error ideológico. Lo mismo en el pensamiento. Quizá la consecuencia más grave de esto culto es que exonera al pensamiento de ser creativo.

\section{AMA: Y ¿crees tú que hay un bolivarianismo letrado y un bolivarianismo popular?}

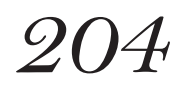

GCD: Desgraciadamente en todo esto se ha terminado como fundiendo, porque se le ha convertido en la ideología oficial. Pero no oficial de un gobierno, sino del Estado. Cambian los gobiernos y eso sigue. Por ejemplo, en el gobierno de Luis Herrera Campins (1979-1984) llegó el culto a Bolívar a un nivel que hacia que eso pareciera a una figura casi artesanal porque se tiene una televisión, tiene una radio, la prensa. Entonces, todo eso de la momificación del culto y es lo que este gobierno ha hecho. No sé si consideraron que en toda la firma que ha recorrido todos dicen que están defendiendo la tierra de Bolívar. iEsto no es tierra nuestra, es la tierra de Bolívar! [risas]. Pero tampoco yo seré injusto si atribuyera esto a una particularidad de los latinoamericanos o de Venezuela, no. Los alemanes hicieron lo mismo, los italianos con Mussolini seguían evocando al Imperio Romano al nivel del mediterráneo. Es decir, los pueblos son inclinados a buscar un refugio para sus angustias en lo que consideran lo más glorioso de su pasado. Esto es bastante normal por eso yo aquí lo cumplí el ordenamiento y cumplí mi trabajo bajo la égida de cosas como estas. No puede darse la prueba más triste de la propia pequeñez de un hombre que su incredulidad para con los grandes hombres. Esto está en [Thomas] Carlyle. Pero, lo que es esto: la obra de un hombre pequeño que se muestra incrédulo a de un grande hombre. $Y$ todos no comprenden la posible crítica a la que podría ser objeto de una autoridad. Porque esto es una realidad: no hay mayor estupidez que tratar de cambiar las creencias de un pueblo cuando no se tiene aún con qué sustituirla. Es un problema muy complejo, no tiene nada de circunstancial, va al 
fondo. Ese es la mayor inclinación en creer que en dudar, eso lo sabe lo lógico completamente. Así como la tendencia del musculo es el reposo, la tendencia del marido es la incredulidad [risas]. Entonces, aceptar las cosas como están más holgado, más fácil que ponerse a pensar...

\section{AMA: En los días actuales ¿qué podríamos entender sobre el concepto de Bolívar de Patria Grande?}

GCD: Mira, Bolívar era un hombre de un pensamiento del siglo XVIII. Él no llegó al siglo XIX, él creía en los universales, la humanidad, la justicia, la verdad y todos sus discursos están basados en esto. Entonces su capacidad de ver todo el mundo hispánico como una misma misión se correspondía con aquél pensamiento. Pero él no era el único, recuérda la constitución política de la monarquía española - que ahora están en vigencia según el primer ministro de España - ¿que es lo que hacen? Habla de los españoles de Europa y de los españoles de América. Una misma nación porque el concepto de nación tiene que ser relacionado con patria y el concepto de país tiene esa relación con el Estado. La gente confunde estas dos cosas. Para que sea una sola nación lo que significa es factores de identificación y sobre todo una memoria histórica que tenga elementos comunes. Fíjate como está ubicada la unidad de la nación germánica y quería unirla, y en el comienzo se empezó a criarla, y por eso se anexo a los reinos porque había que tener a todos los que tenían orígenes germánicos. No pretendían restablecer el Imperio Romano como hizo en el caso del Mediterráneo. Entonces no querían a conquistar el norte de África como el lógico, no. Yo creo que estos son procesos históricos muy normales, lo que no quiero decir es que sean justos o aceptables. Pero el historiador no se plantea las cosas en términos de justicia o de aceptación, sino de autenticidad histórica. Para Bolívar, la idea de que toda América existe en una nación, lo que quiere decir es que todos los latino-americanos tienen elementos comunes. Lo que él había olvidado es que en toda América Latina había por lo menos 150 sociedades que no son de origen hispánicas. Sí, la sociedad guaraní, por ejemplo. En México, si le dices a uno Totonaca o a un Maya que él es un mexicano no les gustará mucho. "Porque yo soy un Totonaca, o un Maya", dicen. Yo conozco muy bien a México, yo fui embajador allá y también estuve exiliado allí. Existe lo que es la antigua civilización Maya, incluye la península de Yucatán y una parte de lo que es Centroamérica casi hasta Honduras. Ellos son Mayas y hablan a su idioma y tienen sus periódicos. Y esta cultura Maya es la cultura más desarrollada y más antigua del Caribe. Sin embargo, los historiadores lo ignoran. Yo tuve la experiencia, cuando era miembro de la dirección del Comité Editorial de Historia del Caribe. Entonces, la gente del Caribe, del Caribe Anglo, considera que ellos son el Caribe. En cambio, en el Caribe Hispánico no cuenta. Y lo que es el Caribe Maya menos todavía. Pero aquí hay que decir, en cambio, ustedes no existían cuando ya los Mayas tenían idioma, numeración y otras cosas. Si algo merece un volumen específico es la cultura y civilización Maya. Por eso yo abandoné el comité, mi consciencia de historiador no me permitía aceptar esto. Esto es un 
punto. Nosotros no somos una sola nación, los hispanoamericanos. Somos varias naciones y por eso la alternativa es la del Estado plurinacional. Pero entonces lo que se dé cuenta en compartir los problemas con alguien que es mestizo, pero no es indígena y que está viviendo el mayor conflicto entre Aimaras y Quechuas que es milenario. Tienen mil años. Son dos culturas que están en legitimidad y en México ha de los Mayas en el sur, por ejemplo, a los Totonacas a los Caraunaras en el norte. Entonces es una distancia de Italia a China. Ahora, ¿Cuál es la América Latina? Son varias las nacionalidades que pueden formar Estados Nacionales, eso es otra cosa. Pero, ustedes [Brasil] tienen el mismo problema. Tiene un Brasil negro, africano, tiene varias sociedades indígenas de todas las líneas. Darcy [Ribeiro] ${ }^{2}$ y yo hablábamos mucho de eso, de las sociedades indígenas y tienen abajo "la pequeña Suiza" con gente del sur...

\section{AMA: Sí, los blancos.}

GCD: De origen suizos además.

\section{AMA: Italianos...}

GCD: Sí, Por eso le digo. Es un universo extraordinario. Nosotros en Venezuela tenemos la ventaja y la desventaja al mismo tiempo. Nuestras sociedades indígenas eran realmente primarias, no construyeron ciudades y eran

206 fundamentalmente cazadores y recolectores y con una estructura propia del paleolítico superior y así permanecieron. No hay una sola ciudad construída por los aborígenes venezolanos. Pero, y si usted va a Perú, va a Bolivia y va a México y más aún va a Yucatán que es único, existe una cultura urbana, hay una gran diferencia entre un mundo y el otro.

\section{AMA: Y por fin, ¿podría haber un culto a Bolívar sin el componente militar?}

GCD: Usted está tocando en el punto más interesante. Mira, a mí se ha ocurrido escribir y lo digo en mis clases cosas que son realmente... casi blasfemia. Por ejemplo: ¿Cuál es el día del Ejército Venezolano? Es el día 24 de julio de 1821 cuando comienza la Batalla de Carabobo que fue cuando "nuestro glorioso Ejército"... los militares son atemporales, son los mismos hasta aquí [risas]... son ellos, estos mismos los que nos dieron la Independencia, la Patria, la libertad. ¿Dónde ellos nos dieron? En Carabobo [risas]. Pero cuando tú estudias la historia te das cuenta de que en Carabobo quien luchó por la independencia fue el Ejército de la República de Colombia. Que había sido fundada en 1821 en Cúcuta dos meses antes. Pero, ¿quién dirigía el Ejército? Un general colombiano, nacido venezolano, Simón Bolívar. Porque Bolívar fue el primer colombiano de la historia. No hubo colombianos antes de Bolívar. La ley fundacional de Colombia se aprobó en Angostura, aquí mismo en el Orinoco, el 17 de diciembre de 1819.

\footnotetext{
2 Darcy Ribeiro (1922-1997), antropólogo, escritor y político brasileño. Enseñó en la Universidad de Brasilia.
} 
Y el artículo primero de esa ley dice: desde el día de hoy, la República de Venezuela y de la Nueva Granada serán reunidas en una sola República que llevará el glorioso nombre de Colombia. Pero cuando Bolívar homologó esta ley, él tenía que promulgarla, la aprobó el Congreso, pero tú sabes que una cosa es la aprobación y otra cosa la promulgación. Cuando él promulgó esta ley y terminó de firmar Simón Bolívar, él fue el primer colombiano. Sí, porque la nación es un resultado de la historia. Pero las formas de la nación pueden venir desde la monarquía absoluta hasta la República. Entonces, ¿Cuál es la República de Colombia? ¿Quién fue el primer colombiano? Simón Bolívar. Porque si usted dice a los militares que ellos no fueron los que ganaran la batalla de Carabobo, sino que fue el Ejército de Colombia... Pero Colombia la fundamos los venezolanos en Angostura. Es la obra máxima de los venezolanos, históricamente, no es la independencia, es haber fundado Colombia. Primer caso en la historia de pueblos que se reúnen, sin violencia, con el objeto de abrir un futuro común. Es el primero caso en la historia. Ni Venezuela conquistó a Nueva Granada ni Nueva Granada conquistó a Venezuela. Y sin embargo se funden en una sola nación. Por eso la ley que se aprueba en Angostura dice: las Repúblicas de Venezuela y de Colombia serán una sola, pero cuando se reúne el Congreso en Colombia y aprueban la ley de la unión de los pueblos de Colombia ya no hablan de República, sino que dice que los pueblos de la antigua Capitanía General de Venezuela y del Virreinato se reúnen en uno solo que es la República de Colombia. Hay una diferencia de nivel. La función de Estados es una cosa, pero cuando ellos se funden en una función de pueblo... entonces ¿dónde comienzan a fundarse las naciones? Con Colombia. Un problema con la historia es que quien la lee críticamente, y sobre todo con conocimiento que va más allá del visual, puede tener tropiezos muy serios. Y eso continúa. En Carabobo se consolidó la independencia de Venezuela, pero es un engaño. Primero, lo que se consolidó fue la independencia de Colombia. Uno de los departamentos era Venezuela. Pero, además, la consolidación de la independencia no sucedió en Carabobo. Sucedió en Bolivia [Perú], en Ayacucho en 1824. Dónde el Ejército de Colombia, con auxiliares peruanos, chilenos, comandados por un general colombiano, nacido en Cumaná, Antonio José de Sucre, terminó con el Imperio Hispanoamericano. ¿Dónde quedan estos 'militarcitos' que creen que son los padres de la patria y los añoran ahora en el país? Ellos cumplieron su papel, no hay dudas, heroicamente. Pero no era verdad que sea el Ejército de Venezuela, este Ejército atemporal como lo he dicho. Eso es un gran fraude. Entonces, lo que se desarrolló aquí fue el Ejército de Colombia: Imagínate el apego popular que me llevo. Porque además que ellos [los militares] miran y justifican su precioso respaldo en Venezuela pretendiendo que la verdadera independencia se logró cuando nos separamos de Colombia. Curiosamente Colombia es la más grande obra de Simón Bolívar. Y nosotros nos 'liberamos' de Bolívar. ¿Esto no te parece que está llamando a contradicciones en estos asuntos?...

11. AMA: Pero no. Porque ya he leído a Manuel Caballero... Entonces, el punto de vista es lo mismo. Por ejemplo, a él no le gusta la palabra quinta República porque 
no hubo la cuarta República. Manuel Caballero, en uno de sus libros, plantea que Venezuela surgió tras la muerte de Bolívar cuando se apartaron los dos países.

GCD: Mira. Manuel Caballero fue mi "hijo". Él estudio historia porque yo lo pedí a su mama y le permitió a estudiar historia. Le tengo en el mejor recuerdo. Era tan amigo mío y yo lo quería tanto que yo hablaba mal de él. Porque yo digo que para querer a alguien hay que hablar mal de él [risas]. Y hoy en día él me hace falta para pelear. Pero Manuel no llegó realmente a formarse una conciencia de historiador. Magnifico escritor, se lee con verdadero gusto. Pero él era capaz de sacrificar el conocimiento a una metáfora. Con una metáfora él quería decir lo todo. Porque él era fundamentalmente un escritor, periodista que llegó a la historia y trasladó a la historia aquél estilo. Y muchos me decían a mí "tú deberías escribir con Manuel para que le llegues a la gente". Yo les respondía que a mi no me interesa llegar a la gente y aquél que no entendía lo que yo entiendo que haga un esfuerzo. Debes escribir con todos los asientos científicos, no puede ser de otra manera. Ahora, le tengo con el mayor respeto y voy a leer a don Manuel con verdadero placer, pero vivía a peleas con él por eso. Porque es brillante, impacta, capta la atención, es verdad, de primera... Pero no desarrolló realmente una mente de historiador. Cuando él estaba ya en las últimas me llamaron y yo fui a la clínica dónde él estaba un poquito antes de morir. Tú sabes que pasamos un par de horas allí planeando el seminario que íbamos hacer juntos. Y yo lo quería mucho. La gente nos veía pelear y creían

208 que era antipatía. No, no, no. Era una manera de amarnos...

\section{MA: Un modo entre amigos.}

GCD: Sí. Por eso te digo, con honor, Manuel fue un gran escritor, un gran periodista, hizo cosas muy buenas, tiene un destello histórico muy valioso, pero no llegó a formarse en la disciplina intelectual, aburrida, pesada de un historiador. Y esto lo digo con veneración y esto lo recuerdo.

13. MA: Es que la gente que no está en su campo, no le exigen a los llamados científicos duros. Al físico jamás le exigen la concepción histórica amplia, al físico le exigen que escriba como un físico.

GCD: Bueno, para mí esto es una idea reconfortante. Y cuando yo veo a Lynch que es capaz de escribir eso: "hay poco libros a los cuales pueda decirse que son modelos de su género". iCaramba! Cuando yo recibí esto de Lynch, me dije, bueno, no perdí tiempo. Tú sabes que los británicos, como decía hace un rato, no son probos al elogio. $Y$ Lynch es de un nivel admirable. Y yo creo para mi, que lo que define el problema del culto a Bolívar no es la esencia misma del fenómeno, sino la actitud que se asuma ante esto. Por eso yo creo que hay que acercarse de Bolívar con el criterio de historiador crítico, y eso es enaltecerlo, no es disminuirlo. Porque era un hombre que fue capaz de revolucionar... el Bolívar esclavista de 1814 se convierte en el Bolívar que plantea, que tan pronto se 
promulgue la Constitución de Bolivia, quita la esclavitud. Pero hay diez años entre un Bolívar y otro. Y es el mismo Bolívar. Porque pasa de un esclavista, él pide ayuda a los ingleses para devolver los esclavos a su nivel, pero diez años después declara la abolición de la esclavitud. Eso es de un honor admirable.

\section{MA: Pero, lo convenció Petión.}

GCD: No, lo convencieron los esclavos alzados que salieron corriendo de Caracas. Y así se dió cuenta que era imposible establecer la República y lograr la independencia sobre la base de una sociedad esclavista. Ese era Bolívar. Entonces, si tú hablas de esclavismo en Simón Bolívar, a comienzo, ¿está contra Bolívar? iNo! Está planteando el hombre como era históricamente. Es él mismo que revoluciona. Existe la famosa frase que todos deben haber oído, la carta de Bolívar a los representantes de su Majestad Británica del año 28 [1828] que dice que "los Estados Unidos están destinados por la providencia a plagar la América de miseria en nombre de la libertad". Entonces, nos encontramos algunos tontos que dicen que Bolívar era antiimperialista. Bolívar, lo que temía, era una realidad, es decir, por aquellos que no habían conocido la libertad. Él temía que el desbordamiento de la libertad pusiera en peligro la independencia. Porque eso haría imposible el establecimiento de la República y la consolidación del nuevo sistema. Pero esto estaba reflejando una situación que no era de ninguna manera única para América Latina. Era la controversia que había en los Estados Unidos entre Washington y Jefferson. Washington era un hombre de pensamiento conservador. $Y$ en este caso es Bolívar. Jefferson estaba entusiasmado con la Revolución Francesa. Entonces, las diferencias entre ellos no eran casuales. Eran dos concepciones. Washington quería consolidar la unión y el otro creía que la consolidación se lograría por la unidad y la plena libertad. Y eso era lo que temía Washington. A eso es a lo que se refiere Bolívar. Pero, como tuvo, el experto en letras y nada más, y no es visto históricamente entonces... este tonto que acaba de morir ahora [Eduardo Galeano] de "Venas abiertas de América Latina"... muestra a Bolívar como un antiimperialista...

15 MA: Él hizo un daño al pensamiento de este continente con un simplismo...

GCD: Y en otro libro. Cuando yo leí en él que los criollos se pegaban a tener esclavos para tener trabajo gratis. Pero, ¿tú tienes idea de algo? Un esclavo de veinte años, joven, con buena salud, valía hasta 400 pesos. Era como comprar un tractor. En cambio una res se podía comprar con 4 pesos. ¿Dónde está el trabajo gratis? Si para tener un esclavo tenía que invertir allí una parte muy considerable de su capital. Entonces, no era trabajo gratis. No tenía idea de lo que estaba hablando. Porque además de invertir el capital, tiene que mantenerlo y cuidarlo. Ustedes, un tractor lo cuidan. Entonces, ¿dónde está el trabajo gratis? Si alguien piensa que el trabajo esclavo era un trabajo gratis, no tiene idea de lo que es la esclavitud. Y Galeano pretendía decirlo en cargo de la historia de América. La ignorancia es grande, sabes, y peligrosísima para los destinos del pueblo. 
16. MA: Aquellos que dicen que la ignorancia es osada.

GCD: Bueno, hay la famosa frase de Einstein: ${ }^{3}$ "la más universal de las leyes es la estupidez"

\section{AMA: Bueno, ya ocupamos demasiado el tiempo de Carrera Damas.}

GCD: Esto para mí es como abrir una llave. Tengo apenas cuarenta años ocupándome, pero ya no escribo más sobre esto.

\section{MA: La llave ya lo cerró.}

GCD: Sí. La cerré y sobre todo porque estoy en retiro porque creo que hay mucha gente que está haciendo cosas buenas. Están tomando aspectos para desarrollarlos... Entonces me siento gratificado. No van a ponerse ahora a decir que fulano dice algo como yo ya lo dije. No, tienen el derecho de decir lo que quieran. La más anticientífica de las posiciones es la quién cree que es que con él se termina el saber. Para mí, la mayor dicha es que lo que uno puede buscar, continúe, sino que lo supere. Pero yo no me inquieto un minuto en llegar abonando el sentido del saber. Yo acabo de publicar un libro sobre Rómulo Betancourt. Todas las liciones se elijen. Ese es un libro en serie. Pero el borrador que este libro tenia aproximadamente 1200 cuartillas. Bueno, como yo

210 consideraba que el tema era importante, le pedí a la fundación Betancourt que ese borrador lo pusiera en la página de la fundación invitando a todo el mundo que hiciera observaciones, críticas, lo que fuera. Pero con absoluta libertad. Pero, se formaron nueve grupos de historiadores, sociólogos, antropólogos y hasta literatos. Y estudiaron el borrador y me entregaron 125 partillas de observaciones, recomendaciones, refutaciones. Yo para redactar el libro, me reuní con el borrador, con el volumen uno, pero antes de entrar y trabajar, hice público el borrador. En dos grupos. Y me reuní con ellos en la fundación. En sesiones desde la nueve de la mañana a la una, en sábado. No para discutir, sino para evaluar las observaciones directamente. Bueno todos tomaban nota. Y luego cuando yo fui a redactar los seis borradores, por supuesto, las observaciones, más las notas que ellos habían hecho, más no que ellos habían pensado ya se fundieron en 1400 partillas. Uno puede decir "tú estás loco, como vais a poner en tu trabajo al alcance de todo el mundo". Y yo digo, "caramba, ahora estoy dirigiendo tres tesis", basadas en el borrador. De profesores, uno está estudiando la cuestión agraria que me interesó muchísimo; otro la cuestión del concepto de soberanía popular que es la base de la democracia; y el otro está estudiando la Doctrina Betancourt, en relaciones internacionales. Están haciendo tesis de doctorado sobre esto. Porque están viendo cosas que yo no ví. Yo las esbocé, y hoy están estudiando en profundidad. Y así salta a uno el 
conocimiento. Te digo, yo no tengo el proyecto de ser dueño de los temas ni nada. Yo he tratado de ser un científico y no hay mayor proposición de falta de sentido científico que las personas que creen que la ciencia termina con ellos.

AMA: Gracias por todo....

Caracas, 15 de abril de 2015.

\section{Referências bibliográficas}

CABALLERO, Manuel. ¿Por qué no soy bolivariano? Une reflexión antipatriótica.

4. ed. Caracas: Alfadil Ediciones, 2007.

CARRERA DAMAS, Germán. El culto a Bolívar: esbozo para un estudio de la historia de las ideas en Venezuela. 7. ed. Caracas: Editorial Alfa, 2013.

. Una nación Ilamada Venezuela. Caracas: Monte Ávila Editores, 1991.

. Historia de la historiografía venezolana. Caracas: Universidad Central de Venezuela, 1985.

Rómulo histórico. Caracas: Alfa, 2013.

CASTRO LEVIA, Luis. De la patria boba a la teología bolivariana. Caracas: Monte Ávila Ediciones, 1987.

GALEANO, Eduardo. Las venas abiertas de América Latina. México: Siglo XXI Ediciones, 2004.

LYNCH, John. Simon Bolívar: a life. New Haven: Yale University Press, 2006.

PINO ITURIETA, Elías. El divino, Bolívar. Caracas: Editorial Alfa, 2014. 